\title{
Electro-Oxidation and Simultaneous Determination of Indole-3-Acetic Acid and Salicylic Acid on Graphene Hydrogel Modified Electrode
}

\author{
Xiaodong Cao ${ }^{1}$, Xueting Zhu ${ }^{1}$, Shudong $\mathrm{He}^{1}$, Xuan $\mathrm{Xu}^{2}$ and Yongkang $\mathrm{Ye}^{1, *(1)}$ \\ 1 School of Food and Biological Engineering, Hefei University of Technology, Hefei 230009, China; \\ xiaodongcao@hfut.edu.cn (X.C.); xuetingzhu25@163.com (X.Z.); shudong.he@hfut.edu.cn (S.H.) \\ 2 School of Chemistry and Molecular Engineering, Nanjing Tech University, Nanjing 211816, China; \\ xuxuan0205@njtech.edu.cn \\ * Correspondence: yongkang.ye@hfut.edu.cn
}

Received: 12 November 2019; Accepted: 11 December 2019; Published: 12 December 2019

\begin{abstract}
A selective and sensitive electrochemical sensor was developed for simultaneous detection of phytohormones indole-3-acetic acid (IAA) and salicylic acid (SA). The sensing interface was fabricated on a porous, three-dimensional networked graphene hydrogel (GH) modified glassy carbon electrode (GCE). The electrocatalytic behavior of IAA and SA on the surface of the modified electrode (GH/GCE) was investigated by cyclic voltammetry and linear sweep voltammetry. Results show that the oxidation reactions of IAA and SA occur at different potentials, which enable their simultaneous detection at the sensing interface. Under optimal conditions, the GH/GCE exhibited good selectivity and stability and its response, unaffected by various interferents, was linear in the range of 4 to $200 \mu \mathrm{M}$ of IAA and SA. The limit of detection $(S / N=3)$ achieved were $1.42 \mu \mathrm{M}$ for IAA and $2.80 \mu \mathrm{M}$ for SA. The sensor performance was validated by measuring for IAA and SA in real vegetable samples with satisfactory results.
\end{abstract}

Keywords: electrochemical sensor; simultaneous detection; indole-3-acetic acid; salicylic acid; graphene hydrogel

\section{Introduction}

Plant hormones, also known as phytohormones, are organic chemicals produced in plants that can regulate physiological processes [1-3]. There are different classes of phytohormones, including abscisic acid, auxin, cytokinins, ethylene, gibberellins, and brassinosteroids. The concentrations of phytohormones present in plants are rather low and they vary during different growth periods. These phytohormones exert their effects in some complex and synergic ways and control all aspects of plant development-from embryogenesis, the regulation of organ size, pathogen defense, stress tolerance, and through to reproductive development [4]. Therefore, there is a need to develop simple and sensitive methods to detect and analyze phytohormones in plants [5]. Furthermore, there is an increasing interest now on analysis of multiple phytohormones, rather than a specific one [6].

The most powerful tools to simultaneously identify and determine multiple phytohormones are chromatographic techniques combined with sensitive detectors or tandem mass spectrometry [7-11]. Although such techniques possess advantages of excellent sensitivity and selectivity, efficient separation, and fast determination, they are limited to complicated and time-consuming sample preparation methods and require expensive apparatus to perform the test. Over the past decade, researchers have been pursuing alternative methods for the determination of phytohormones, including fluorescence spectrometry [1], enzyme-linked immunosorbent assay [12], and electrochemical analysis [13-15]. 
Among these, the electrochemical biosensors are the most promising given their inherent advantages of being simple, sensitive, rapid, portable, and cost-effective $[11,13,14,16]$.

Indole-3-acetic acid (IAA) is the first identified auxin, which is regarded as the most important phytohormone [17]. IAA participates in the entire plant growth and development processes. It has been shown that IAA plays vital roles by interacting with other phytohormones under different conditions and asserting its effect on plant development [18]. Salicylic acid (SA), is also an indispensable phytohormone. SA plays a critical role in meditating the response of plants to abiotic stresses such as drought, temperature, heavy metal, and osmotic [19]. Some evidence shows that the crosstalk between SA and IAA signaling during the growth of plants is concentration dependent [19-21]. Therefore, it is necessary to develop simple, rapid, and sensitive methods to simultaneously detect and determine IAA and SA in plants.

In the last few years, several sensors have been fabricated on various nanomaterials to detect IAA and SA, especially using electrochemical methods [22,23]. A multiwalled carbon nanotubes-chitosan modified glassy carbon electrodes (GCE) was developed to detect both IAA and SA simultaneously in the range of 0.67 to $49 \mu \mathrm{M}$ with a limit of detection (LOD) of $0.1 \mu \mathrm{M}$ by using differential pulse voltammetry [23]. An electrochemical sensor, fabricated on a working electrode of carbon tape modified with carbon nanotubes, was used to monitor the amounts of IAA and SA during the development of pea roots [4].

Three-dimensional (3D) graphene materials which can be assembled by graphene nanosheets, have improved physical and electrochemical properties when compared to graphene nanosheets [24-26]. In recent years, they have gained great attention because of their high specific surface area, good electron mobility, porous, and 3D-networked structure [27-29]. Graphene hydrogel (GH) is a 3D graphene material that can be prepared easily by hydrothermal reduction [30-32] and chemical reduction [33,34]. To date, GH has been used in supercapacitors [30,34,35] and electrochemical sensors [36-39]. GH-based nanocomposites show excellent electrocatalytic activity to the oxidation of ascorbic acid (AA), dopamine (DA), and uric acid (UA), which has been used in their simultaneous detection in human serum samples [31,32]. In our previous work, we prepared gold nanoparticle-doped GH using hydrothermal method at temperatures higher than $100{ }^{\circ} \mathrm{C}$, and its properties were investigated with various characterization methods. Furthermore, our work showed that it can be applied for amperometric determination of IAA and SA [36].

Herein, we prepared GH using the hydrothermal method at a relatively low temperature. Taking advantage of the porous and 3D-networked structure of GH, we constructed an electrochemical sensor for simultaneous detection of IAA and SA on a GH modified GCE (GH/GCE) (Scheme 1), and the electrooxidation behavior of IAA/SA were investigated as well. After the absorption on the GH/GCE, IAA and SA are readily oxidized within the potential window at different potentials facilitating their selective and simultaneous detection and quantification.

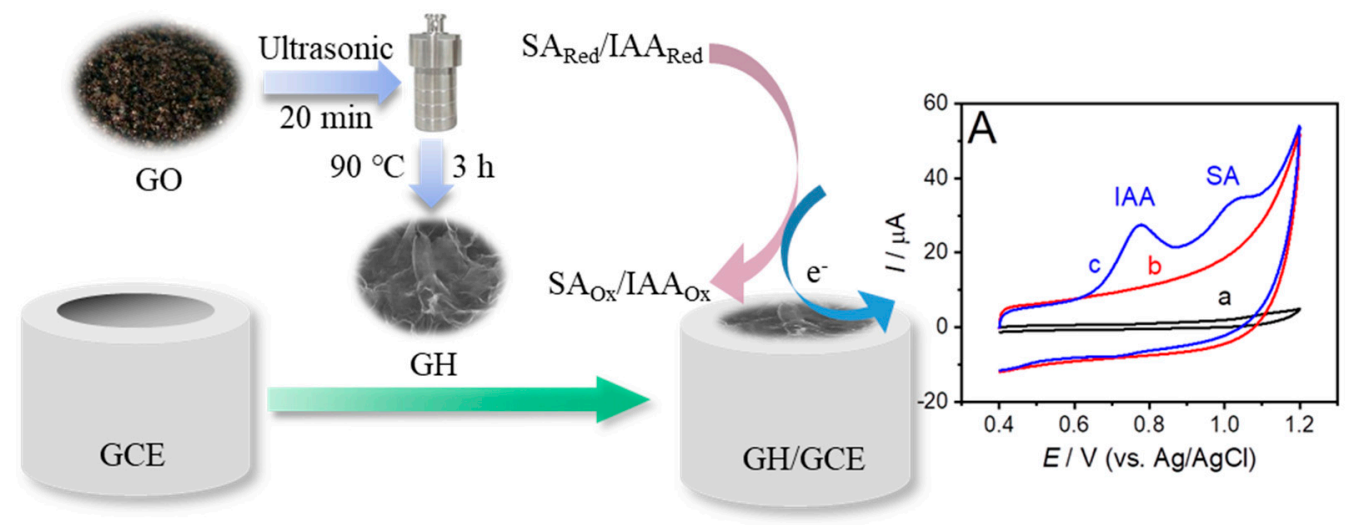

Scheme 1. Preparation and detection procedures of the indole-3-acetic acid/salicylic acid (IAA/SA) sensor. 


\section{Experiment}

\subsection{Materials and Reagents}

Graphite oxide was purchased from Nanjing Jicang Nano Technology Co., Ltd. (Nanjing, China). Nafion was bought from Sigma-Aldrich (St. Louis, MO, USA). IAA, SA, L-Cysteine (L-Cys), L-Tyrosine (L-Tyr), L-Tryptophane (L-Trp), L-Malic acid, citric acid (CA), abscisic acid (ABA), gibberellic acid (GA3), and sodium ascorbate were supplied by Aladdin (Shanghai, China). The 0.10 M stock solutions of IAA and SA were prepared using anhydrous ethanol and stored in a refrigerator. Phosphate buffer solution was prepared by mixing stock solutions of $\mathrm{Na}_{2} \mathrm{HPO}_{4}$ and $\mathrm{NaH}_{2} \mathrm{PO}_{4}$, and then adjusted to the desired $\mathrm{pH}$ by $0.10 \mathrm{M} \mathrm{H}_{3} \mathrm{PO}_{4}$. All other chemicals were of analytical grade and used as received. Deionized (DI) water was used all through the experiment.

\subsection{Apparatus}

Field emission scanning electron microscopy (SEM) images were obtained with SU8020 (Hitachi, Tokoyo, Japan) at an accelerate voltage of $5 \mathrm{kV}$. Raman characterization was measured on a LabRam HR Evolution (HORIBA Jobin Yvon, Paris, France) at the $\lambda_{\text {exc }}$ of $532 \mathrm{~nm}$.

Electrochemical characterizations and measurements were performed on a CHI 660D electrochemical workstation (Shanghai Chenhua, Shanghai, China) with a standard three-electrode configuration. A platinum wire provided the counter electrode, an $\mathrm{Ag} / \mathrm{AgCl}$ electrode acted as the reference, and the $3 \mathrm{~mm}$ diameter GH modified GCE (GH/GCE) was used as the working electrode. Electrochemical impedance spectroscopy (EIS) measurements were conducted in $0.10 \mathrm{M} \mathrm{KCl} \mathrm{containing}$ $5 \mathrm{mM}(\mathrm{Fe}(\mathrm{CN}))^{3-/ 4-}$ with the frequency ranging from $0.1 \mathrm{~Hz}$ to $10 \mathrm{kHz}$. The electrochemical behaviors of IAA and SA were investigated by cyclic voltammetry (CV) in a $5.0 \mathrm{~mL}$ phosphate buffer $(0.10 \mathrm{M}$, $\mathrm{pH} 2.5$ ) at the scan rate of $100 \mathrm{mV} \mathrm{s}^{-1}$, either in the potential window 1.20 to $-0.40 \mathrm{~V}$ with the initial potential of $-0.40 \mathrm{~V}$, or in 1.20 to $0.40 \mathrm{~V}$ window with the initial potential of $0.40 \mathrm{~V}$. Linear sweep voltammetry (LSV) measurements for simultaneous determination of IAA and SA were performed in a $5 \mathrm{~mL}$ phosphate buffer spiked with various known concentrations of IAA (4-200 $\mu \mathrm{M})$ and SA $(4-200 \mu \mathrm{M})$ at the scan rate of $100 \mathrm{mV} \mathrm{s}^{-1}$ within a potential window of 0.40 to $1.20 \mathrm{~V}$. An absorption procedure of IAA and SA onto the surface of the GH/GCE was performed by dipping the electrode in the above phosphate buffer solution dispersions containing various concentrations of IAA and SA under stirring for $150 \mathrm{~s}$ before conducting CV and LSV measurements. Chronoamperometry was used to investigate interference of other substances of IAA and SA. The amperometric responses of possible interfering substances to IAA and SA were measured at the optimized potentials of 0.80 and $1.00 \mathrm{~V}$, respectively.

\subsection{Procedures}

\subsubsection{Synthesis of GH}

Graphene oxide (GO) suspension was obtained by ultrasonication of graphite oxide $\left(3.0 \mathrm{mg} \mathrm{mL}^{-1}\right)$ according to the published method $[40,41]$. The suspension was then dried for later use. The GH was prepared according to Xie et al. with minor modification [33]. Typically, $10.0 \mathrm{~mL}$ of GO suspension (1.20 mg mL $\mathrm{mL}^{-1}$ ) was sonicated for $20 \mathrm{~min}$, and then $66.0 \mathrm{mg}$ of sodium ascorbate was added under ultrasonication. The $\mathrm{pH}$ of the above dispersion was adjusted by using $\mathrm{NaOH}$ or $\mathrm{H}_{2} \mathrm{SO}_{4}$ solution to $3.5,5.3,7.4$ and 9.5, respectively. The mixture was sealed in an autoclave and heated at $90{ }^{\circ} \mathrm{C}$ for $3 \mathrm{~h}$ to form the GHs. The GH obtained were freeze-dried for $24 \mathrm{~h}$ to form the GH powder. The as-prepared GHs were respectively denoted as GH-3.5, GH-5.3, GH-7.4 and GH-9.5, where the numbers represent the solution $\mathrm{pH}$ during preparation. 


\subsubsection{Preparation of GH Modified GCE}

The GCE was polished with 0.10 and $0.05 \mu \mathrm{M}$ alumina slurry and sequentially cleaned by sonication with acetone, ethanol, and water. The GH powder $(1.0 \mathrm{mg})$ was dispersed in $2.0 \mathrm{~mL}$ Nafion $(0.2 \%)$ solution by ultrasonication to form a GH solution of $0.5 \mathrm{mg} \mathrm{mL}^{-1}$. Then, $5.0 \mu \mathrm{L}$ of the GH solution was dropped onto the surface of GCE. The GH/GCE were dried at room temperature. The GO/GCE and bare GCE were also prepared as control electrodes.

\subsection{Sample Analysis}

Celery and young tomato plant leaves were acquired locally in Hefei, China. They were cut and ground into a fine powder in the presence of liquid nitrogen. Then, $2.0 \mathrm{~mL}$ of pre-chilled methanol $\left(4{ }^{\circ} \mathrm{C}, 80 \%\right)$ was added into the powdered sample $(0.5 \mathrm{~g})$ under shaking at $4{ }^{\circ} \mathrm{C}$ overnight, after which $1.0 \mathrm{~mL}$ of $\mathrm{CHCl}_{3}$ was added and the mixture was shaken for another $4 \mathrm{~min}$. Finally, the mixture was centrifuged at 12,000 $\mathrm{rpm}$ for $5 \mathrm{~min}$ under $4{ }^{\circ} \mathrm{C}$. The supernatant was collected and dried at room temperature under nitrogen. The detection samples were prepared by dissolving the dried extractions with anhydrous ethanol and then diluting with a phosphate buffer solution (0.1 M, pH 2.5) to a final volume of $5.0 \mathrm{~mL}$.

\section{Results and Discussion}

\subsection{Characterization of $G H$}

The morphology of the GHs prepared under different $\mathrm{pH}$ values were characterized by SEM (Figure 1). All GHs showed porous 3D-networked structure, though the $\mathrm{pH}$ value at which they were prepared affected the internal structure significantly. The GH-3.5 (Figure 1A) and GH-5.3 (Figure 1B) samples exhibited dense and fluffy structure, and the pore walls consisted layers of stacked graphene unbroken nanosheets. In GH-7.4 (Figure 1C) and GH-9.5 (Figure 1D) samples, the porous structure was uncompacted, and the pore walls were cracked. These indicate that the GHs prepared at low $\mathrm{pHs}$ had better mechanical property than those prepared at high $\mathrm{pHs}$ [33], which we attribute to the high density of the networked structure and stacking of graphene nanosheets.
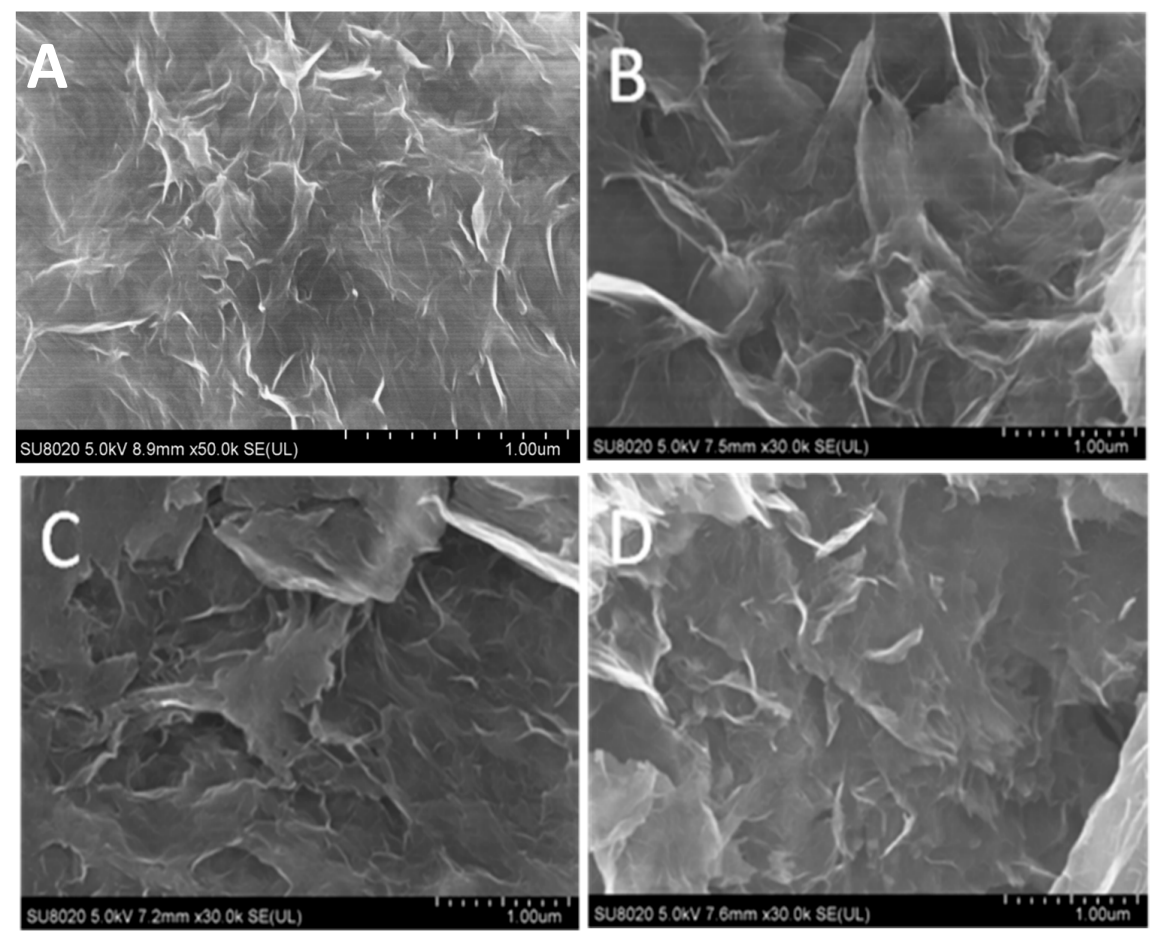

Figure 1. SEM images of (A) graphene hydrogel (GH)-3.5, (B) GH-5.3, (C) GH-7.4, and (D) GH-9.5. 
Figure 2A shows the typical Raman spectra of GO and GH-3.5, which displays two characteristic bands at about 1350 ( $\mathrm{D}$ band) and $1600 \mathrm{~cm}^{-1}$ ( $\mathrm{G}$ band). The $\mathrm{D}$ band corresponds to the $\mathrm{A}_{1 \mathrm{~g}}$ breathing mode of the six-atom ring ( $\mathrm{sp}^{3}$ bonded carbons), and the $\mathrm{G}$ band relates to the high frequency $\mathrm{E}_{2 \mathrm{~g}}$ phonon of the $\mathrm{sp}^{2}$ bonded carbons [42,43]. According to the Raman spectra, the $\mathrm{I}_{\mathrm{D}} / \mathrm{I}_{\mathrm{G}}$ ratio in GH is 1.34 , while that of GO is 0.86 . This indicates a decrease in the average size of $\mathrm{sp}^{2}$ sites in $\mathrm{GH}$ and alteration in the structure of GO during the reduction process with increasing structural defects [44,45]. The GH-3.5 was also characterized by EIS. As can be seen in Figure 2B, the inset is a fitting simulation circuit of the Nyquist spectrum of EIS, the fitting data are listed in Table S1 (Support Information). Here, the constant phase element (CPE) is defined by two values, CPE-T and CPE-P. CPE-P can indicate how close it is to a standard capacitor. If CPE-P equals 1 then the CPE is identical to that of a capacitor. The solution resistance $R_{\mathrm{S}}$ values obtained at three electrodes are quite close. The values of the electron transfer resistance $R_{\mathrm{ct}}$ are $82.8 \pm 5.1 \Omega$ (bare GCE), $119.2 \pm 3.7 \Omega$ (GH-3.5/GCE), and 169.6 $\pm 5.6 \Omega$ (GO/GCE). This indicates that GH-3.5 is more conductive than GO, which makes it a potential nanomaterial in sensor fabrication.
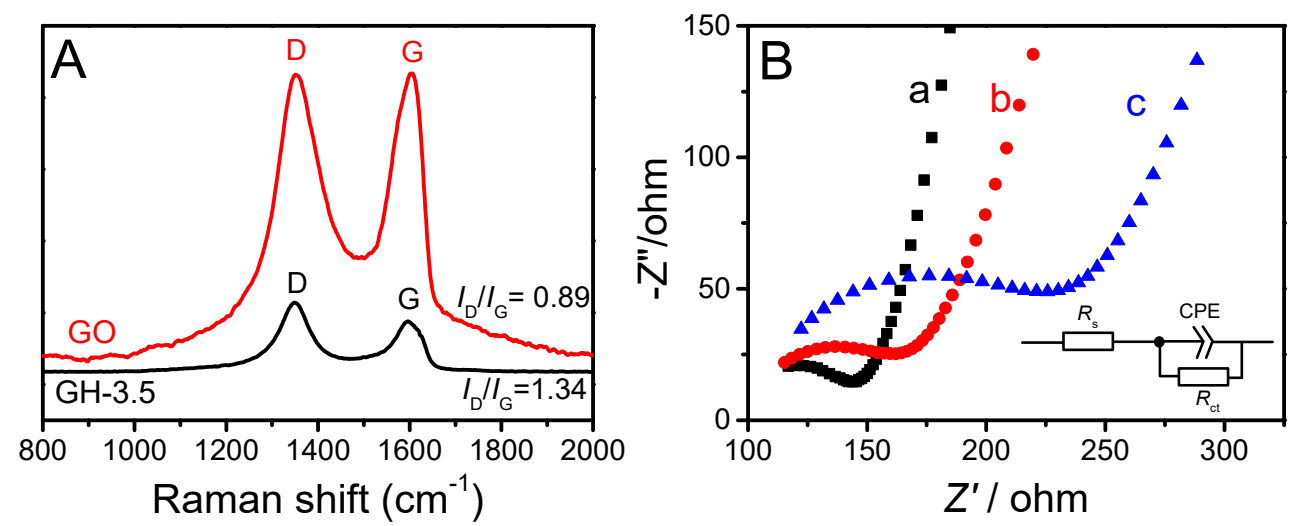

Figure 2. (A) Typical Raman spectra of GO and GH-3.5. (B) Nyquist plots of bare GCE (a), GH-3.5/GCE (b), and GO/GCE (c), inset shows the equivalent circuit used for fitting the impedance data.

\subsection{Electrochemical Oxidation of IAA and $S A$ on $G H / G C E$}

The electrochemical behaviors of $40.0 \mu \mathrm{M}$ IAA and $20.0 \mu \mathrm{M}$ SA in a $0.10 \mathrm{M} \mathrm{pH} 2.5$ phosphate buffer solution at GH/GCE were investigated by $\mathrm{CV}$ in a potential range from 0.4 to $1.2 \mathrm{~V}$ (Figure $3 \mathrm{~A}$ ). No redox peaks were observed on bare and GH modified GCE in $0.10 \mathrm{M} \mathrm{pH} 2.5$ phosphate buffer solution without IAA and SA. However, after absorption of IAA and SA for $150 \mathrm{~s}$, there were two obvious peaks at about 0.78 and $1.00 \mathrm{~V}$ at GH/GCE in buffer solution containing $40.0 \mu \mathrm{M}$ IAA and $20.0 \mu \mathrm{M}$ SA. Based on the literature, the peak at $0.78 \mathrm{~V}$ was assigned to IAA and the peak at $1.00 \mathrm{~V}$ to SA $[23,24]$. The oxidation peak currents of IAA (Figure 4A) and SA (Figure 4C) increased with the increase of $v$ from 25 to $175 \mathrm{mV} \mathrm{s}^{-1}$, and the $E_{\mathrm{pa}}$ shifted positively with the increasing scan rate. The relationships between $i_{\mathrm{pa}}$ of IAA (Figure $4 \mathrm{~A}$, inset) and SA (Figure 4C, inset) were linear with scan rate. These indicate that the irreversible electrode reactions of IAA and SA were adsorption controlled [23]. Meanwhile, the oxidation peak potentials $\left(E_{\mathrm{pa}}\right)$ of IAA/SA were linearly with $\ln v$ (Figure 4B,D), which were in accordance with Laviron's Equation [46]:

$$
E_{\mathrm{p}}=E^{0}+\frac{R T}{\alpha n F} \ln \left(\frac{R T k^{0}}{\alpha n F}\right)-\frac{R T}{\alpha n F} \ln v
$$

where $\alpha$ is the transfer coefficient, $k^{0}$ is the apparent rate constant of the surface reaction, $v$ is the scan rate and $E^{0}$ is the formal potential. Assuming $\alpha=0.5$, the electrons involved in the oxidation of IAA and SA were calculated to be $\approx 2$. Moreover, the electrochemical oxidation reaction of IAA/SA on $\mathrm{GH} / \mathrm{GCE}$ was also affected by the $\mathrm{pH}$ value of phosphate buffer solution (Figure S1, Supporting Information). The oxidation peak of IAA/SA shifted negatively with the increasing $\mathrm{pH}$, indicating 
a proton involved reaction. The irreversible reaction of IAA/SA on the surface of GH/GCE may participate as two electrons and one proton [23], which can be expressed as follows (Figure 3B,C):

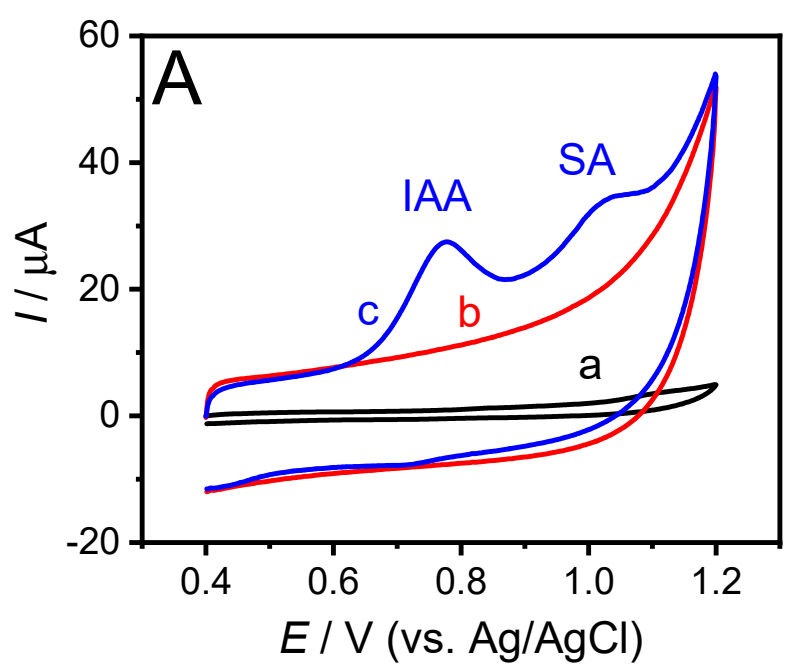<smiles>O=C(O)CC1CNc2ccccc21</smiles>

IAA<smiles>O=C(O)/C=C1\C=Nc2ccccc21</smiles><smiles>Cc1ccccc1C(=O)O</smiles>

SA

Figure 3. (A) Cyclic voltammetry curves (CVs) of bare glassy carbon electrode (GCE) and GH-3.5/GCE in the absence of IAA and SA in $0.1 \mathrm{M} \mathrm{pH} 2.5$ phosphate buffer solution, and CV of GH-3.5/GCE in the presence of $40 \mu \mathrm{M}$ IAA and $20 \mu \mathrm{M}$ SA in $0.1 \mathrm{M} \mathrm{pH} 2.5$ phosphate buffer solution Scan rate: $100 \mathrm{mV} \mathrm{s}^{-1}$. (B) Possible electrochemical oxidation reactions of IAA and (C) SA.

Afterword, the improved response of IAA/SA at GH/GCE was investigated by LSV measurement. Figure 5 illustrates the electrocatalytic ability of bare GCE, GO/GCE, and GH-3.5/GCE to IAA $(80 \mu \mathrm{M})$ and SA $(80 \mu \mathrm{M})$ by the LSV measurement within a potential window from 0.4 to $1.2 \mathrm{~V}$. No oxidation peak observed on bare GCE in the absence of IAA and SA, which agreed with the result of CV measurement (Figure 5, curve a). Broad oxidation peaks appeared on the bare GCE (Figure 5, curve b) and GO (Figure 5, curve c) modified GCE in the presence of IAA and SA. The peaks observed on bare GCE and GO/GCE were located at about 1.13 and $1.09 \mathrm{~V}$, respectively. However, two obvious and separate oxidation peaks at about 0.78 and $1.00 \mathrm{~V}$ were present at GH-3.5/GCE (Figure 5, curve d). The negative shifts of these oxidation peaks indicate that IAA and SA can be oxidized easier on GH modified GCE than on bare and GO modified GCE. The improved electrocatalytic catalytic ability of GH to IAA and SA may due to the increasing defect of GH synthesized from chemical reduction of GO. Furthermore, the peak currents at GH-3.5/GCE were much higher than those at GO/GCE and bare GCE. This indicates that GH/GCE is much more sensitive to IAA and SA than the other two electrodes. 

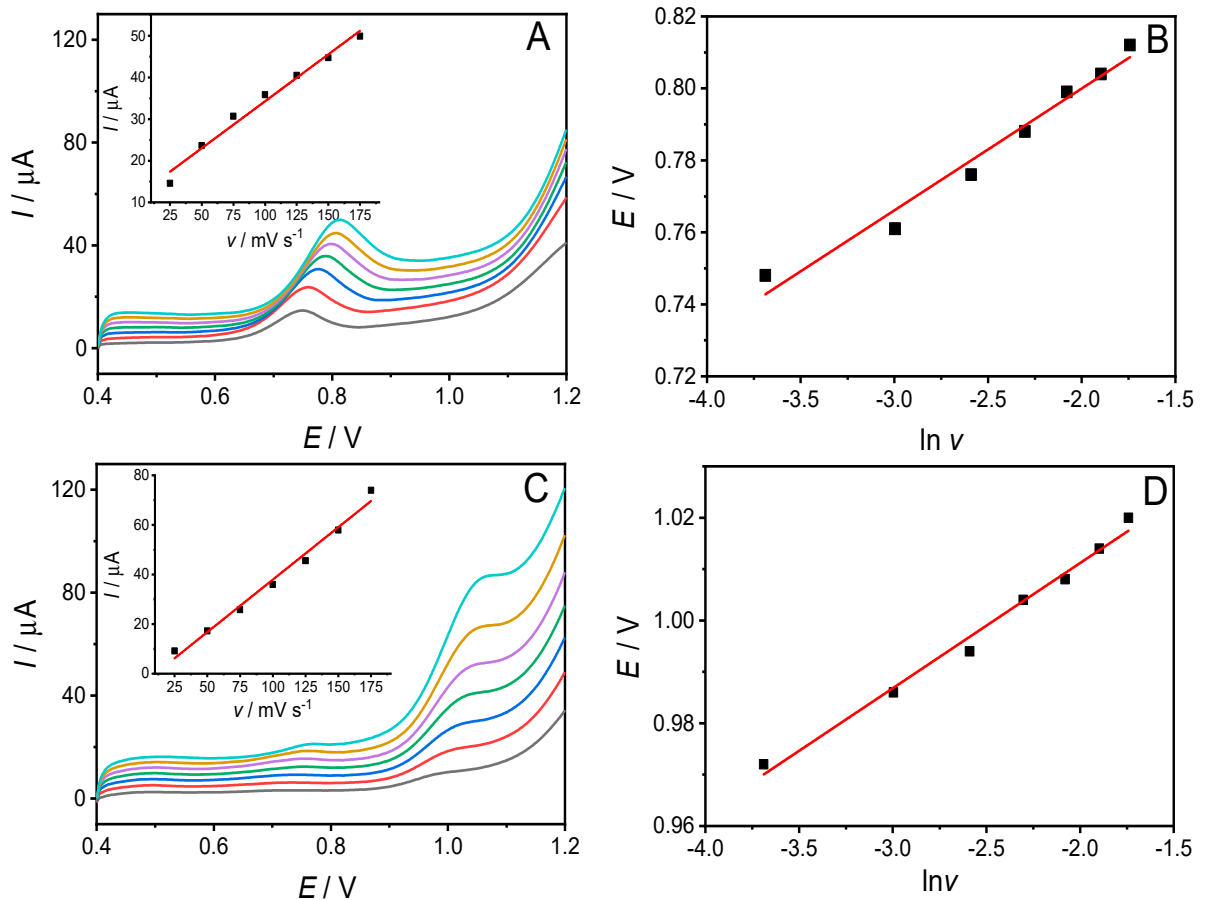

Figure 4. (A) CVs of IAA at GH/GCE with scan rate (v) from 25 to $175 \mathrm{mV} \mathrm{s}^{-1}$ (from bottom to top). Inset: The linear relationship between $i_{\mathrm{pa}}$ and $v$. (B) The relationship between $E_{\mathrm{pa}}$ of IAA and $\ln v$. (C) CVs of SA at GH/GCE with $v$ from 25 to $175 \mathrm{mV} \mathrm{s}^{-1}$ (from bottom to top). Inset: The linear relationship between $i_{\mathrm{pa}}$ and $v$. (D) The relationship between $E_{\mathrm{pa}}$ of SA and $\ln v$.

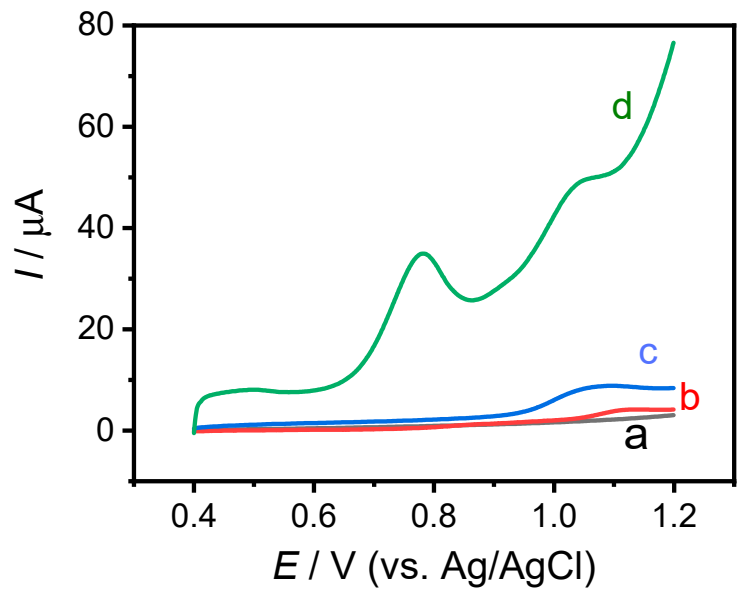

Figure 5. Linear sweep voltammetry curves (LSVs) recorded on different electrodes in $0.1 \mathrm{M} \mathrm{pH} 2.5$ phosphate buffer solution at scan rate of $100 \mathrm{mV} \mathrm{s}^{-1}$. (a,b) bare GCE in the absence and presence of IAA $(80 \mu \mathrm{M})$ and SA $(80 \mu \mathrm{M})$, respectively; (c) GO/CCE in the presence of IAA $(80 \mu \mathrm{M})$ and SA $(80 \mu \mathrm{M})$; and (d) GH-3.5/GCE the presence of IAA $(80 \mu \mathrm{M})$ and SA $(80 \mu \mathrm{M})$. Scan rate: $100 \mathrm{mV} \mathrm{s}^{-1}$.

\subsection{Electrochemical Detection of IAA and $S A$}

As can be also observed in Figure S1, the oxidation peak current of IAA/SA decreased sharply with increasing $\mathrm{pH}$ from 2.5 to 4.5 . Moreover, the oxidation peak of SA almost disappeared when the $\mathrm{pH}$ value of phosphate buffer solution increased to 4.5. The $\mathrm{pH}$ value of $\mathrm{GH}$ preparation showed an effect on the analytical performance of the chemical sensor as well. The GH-3.5 gave the best electrocatalytic performance towards IAA/SA in the detecting buffer with a $\mathrm{pH}$ value of 2.5 (Figure S2, Supporting Information). Thus, GH-3.5/GCE and the detecting buffer of $\mathrm{pH} 2.5$ were used in the detection of IAA and SA afterward. 
The individual detection of IAA and SA on GH/GCE were carried out by LSV measurement. As shown in Figure 6, using the IAA and SA mixture when increasing the concentration of one and keeping the other unchanged, the oxidation peak current increased linearly with changing constituent, unaffected by the unchanged constituent. For example, in the presence of $6.0 \mu \mathrm{M} \mathrm{SA}$, IAA can be detected from 4.0 to $200.0 \mu \mathrm{M}$ (Figure $6 \mathrm{~A}, \mathrm{~B}$ ), and in the presence of $6.0 \mu \mathrm{M}$ IAA, SA can be detected from 6.0 to $300.0 \mu \mathrm{M}$ in phosphate buffer solution (Figure $6 \mathrm{C}, \mathrm{D})$, with LODs $(S / N=3)$ of $1.43 \mu \mathrm{M}$ for IAA, and $1.79 \mu \mathrm{M}$ for SA. The linear relationship between the sensor current $(I, \mu \mathrm{A})$ and target concentration $(C, \mu \mathrm{M})$ are as follows:

$$
\begin{gathered}
\text { For IAA: } I_{\mathrm{IAA}}=0.25 C_{\mathrm{IAA}}+4.21\left(R^{2}=0.999\right) \\
\text { For SA: } I_{\mathrm{SA}}=0.22 C_{\mathrm{SA}}+4.65\left(R^{2}=0.997\right)
\end{gathered}
$$
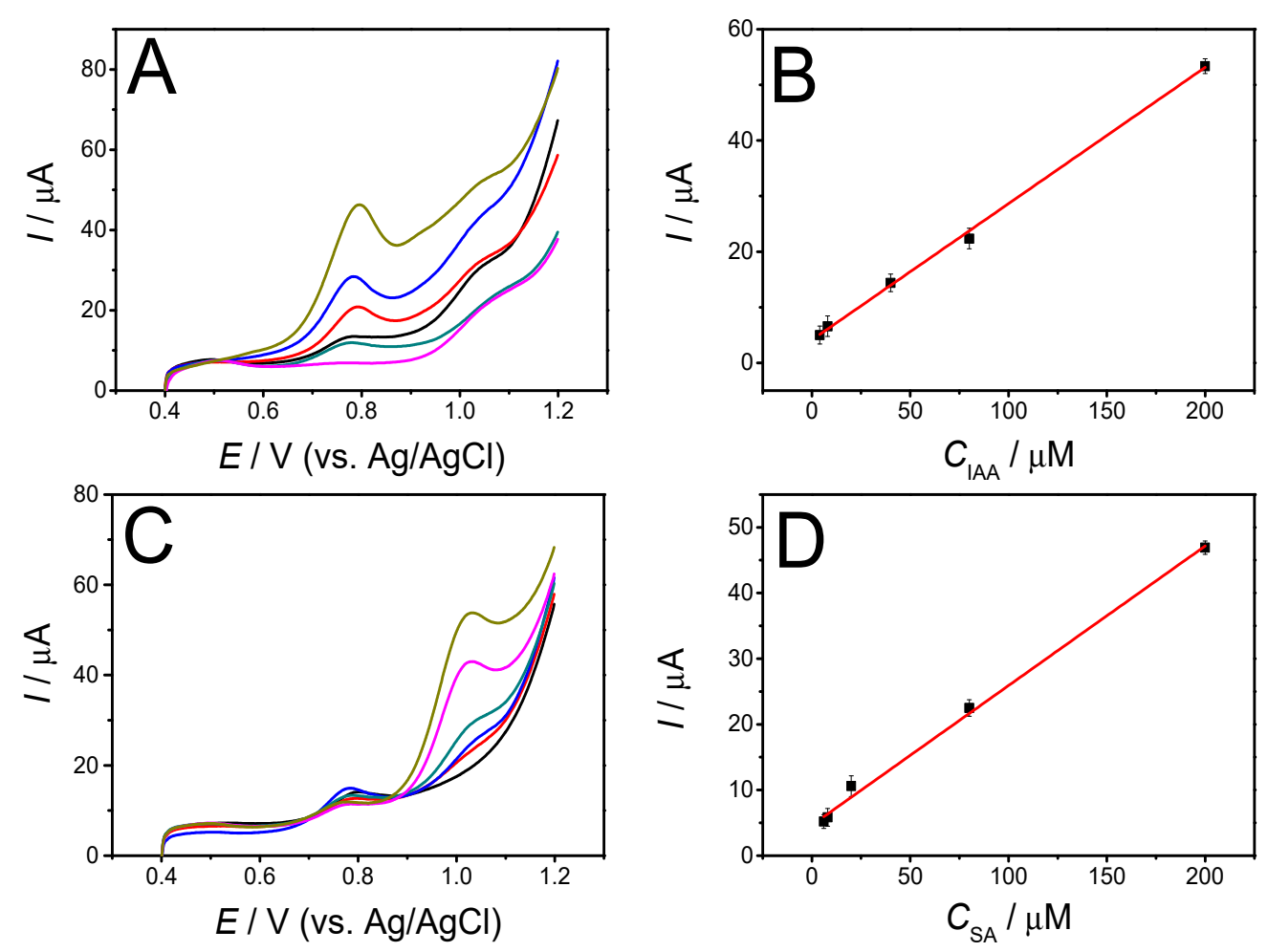

Figure 6. (A) LSVs on GH/GCE in $0.1 \mathrm{M}$ pH 2.5 phosphate buffer solution containing different concentrations of IAA (from 4 to $200 \mu \mathrm{M}$ ). The LSVs were obtained in the presence of $6 \mu \mathrm{M} \mathrm{SA}$ at the scan rate of $100 \mathrm{mV} \mathrm{s}^{-1}$. (B) Calibration curve between anodic peak current of IAA and the concentration of IAA. (C) LSVs on GH/GCE in $0.1 \mathrm{M} \mathrm{pH} 2.5$ phosphate buffer solution containing different concentrations of SA (from 6 to $300 \mu \mathrm{M}$ ). LSVs were obtained in the presence of $6 \mu \mathrm{M}$ IAA at the scan rate of $100 \mathrm{mV} \mathrm{s}^{-1}$. (D) Calibration curve between anodic peak current of SA and the concentration of SA.

The results of simultaneous determination of both IAA and SA are shown in Figure 7. The oxidation peak currents at different potentials of IAA and SA increased simultaneously with increasing concentrations, with LODs $(S / N=3)$ of $1.42 \mu \mathrm{M}$ for IAA and $2.80 \mu \mathrm{M}$ for SA. The linear calibration curves of IAA and SA in the tested concentration range from 4.0 to $200.0 \mu \mathrm{M}$ are as follows:

$$
\begin{aligned}
& \text { For IAA: } I_{\mathrm{IAA}}=0.25 C_{\mathrm{IAA}}+4.43\left(R^{2}=0.997\right) \\
& \text { For SA: } I_{\mathrm{SA}}=0.14 C_{\mathrm{SA}}+4.36\left(R^{2}=0.972\right)
\end{aligned}
$$



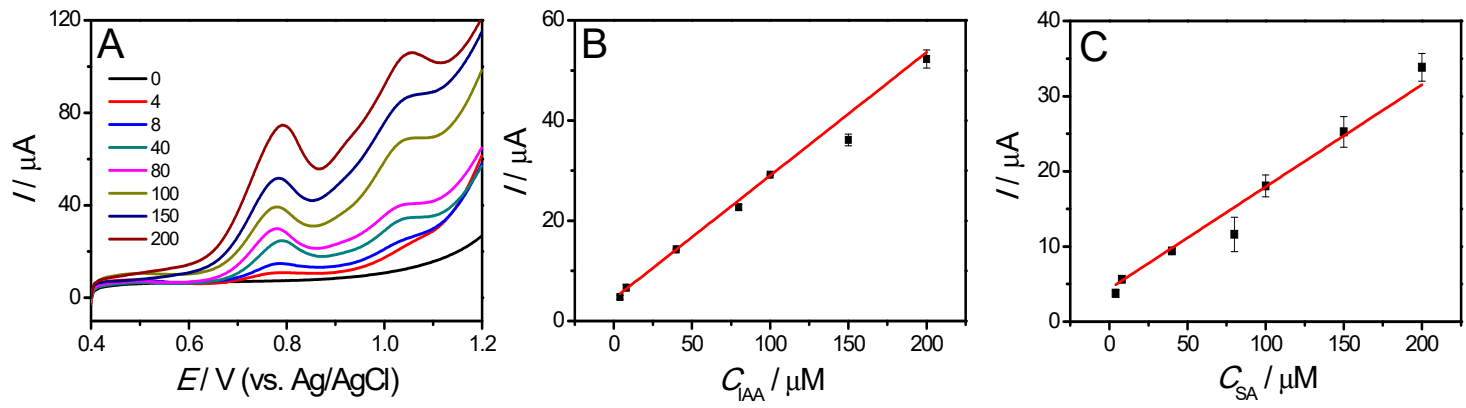

Figure 7. (A) LSVs on GH/GCE in $0.1 \mathrm{M} \mathrm{pH} 2.5$ phosphate buffer solution containing various concentrations of IAA and SA. Scan rate: $100 \mathrm{mV} \mathrm{s}^{-1}$. (B) Calibration curve between anodic peak current of IAA and the concentration of IAA. (C) Calibration curve between anodic peak current of SA and the concentration of SA.

The performance characteristics of our sensor, i.e., linear range and LOD, are comparable to those of other electrochemical sensors for both simultaneous and individual detection of IAA and SA (Table 1). Our sensor also exhibited good analytical performance in detecting IAA/SA.

Table 1. Performance of different electrochemical sensors for the detection of IAA and/or SA.

\begin{tabular}{|c|c|c|c|c|c|c|}
\hline Electrode * & Substance & Potential/V & Method & Linear Range $/ \mu \mathrm{M}$ & $\mathrm{LOD} / \mu \mathrm{M}$ & Ref. \\
\hline CMC-MMT-SWCNT/GCE & $\begin{array}{l}\text { IAA } \\
\text { SA }\end{array}$ & $\begin{array}{l}0.89 \text { (vs. SCE) } \\
1.18 \text { (vs. SCE) }\end{array}$ & LSV & $\begin{array}{c}0.005-0.30,0.30-70.0 \text { (with } \\
80 \mu \mathrm{M} \mathrm{SA} \text { ) } \\
0.01-300 \text { (with } 40 \mu \mathrm{M} \text { IAA) }\end{array}$ & $\begin{array}{c}0.002 \\
0.0063\end{array}$ & [23] \\
\hline MWCNT-CS/GCE & $\begin{array}{c}\text { IAA } \\
\text { SA }\end{array}$ & $\begin{array}{l}0.72 \text { (vs. SCE) } \\
0.88 \text { (vs. SCE) }\end{array}$ & DPV & $\begin{array}{l}0.67-48.82 \\
0.67-48.82 \\
\end{array}$ & $\begin{array}{l}0.10 \\
0.10 \\
\end{array}$ & [22] \\
\hline BDD & IAA & 0.93 (vs. $\mathrm{Ag} / \mathrm{AgCl}$ ) & SWV & $5-50$ & 1.22 & {$[47]$} \\
\hline SPE & SA & - & SWV & $16-300$ & 5.60 & {$[48]$} \\
\hline CNT-PABS/MAGNP/PADC/ITO & SA & 1.14 (vs. $\mathrm{Ag} / \mathrm{AgCl}$ ) & $\mathrm{CV}$ & $6-100$ & 0.105 & [49] \\
\hline $\mathrm{Au} @ \mathrm{Fe}_{3} \mathrm{O}_{4} / \mathrm{GCE}$ & SA & - & DPV & $1.0-1200.0$ & 0.10 & [50] \\
\hline CFE & SA & - & DPV & $2.0-3000.0$ & 1.68 & [51] \\
\hline $\mathrm{PNP} / \mathrm{Pt}$ & SA & - & $i-t$ & $20-500$ & 6.40 & [52] \\
\hline GH/GCE & $\begin{array}{l}\text { IAA } \\
\text { SA }\end{array}$ & $\begin{array}{l}0.78 \text { (vs. } \mathrm{Ag} / \mathrm{AgCl} \text { ) } \\
1.00 \text { (vs. } \mathrm{Ag} / \mathrm{AgCl} \text { ) }\end{array}$ & LSV & $\begin{array}{l}4-200 \\
4-200\end{array}$ & $\begin{array}{l}1.42 \\
2.80\end{array}$ & $\begin{array}{l}\text { This } \\
\text { work }\end{array}$ \\
\hline
\end{tabular}

* Carboxymethyl cellulose (CMC), montmorillonite (MMT), and single-walled carbon nanotube (SWCNT) modified GCE; multiwalled carbon nanotubes (MWCNT)-chitosan (CS) modified GCE; boron-doped diamond electrode (BDD); carbon paste electrode (SPE); anionic carbon nanotubes (CNT-PABS), cationic iron oxide nanoparticles (MAGNP), and cationic poly(diallyl dimethylammonium) hydrochloride (PDAC) modified indium doped tin oxide (ITO) substrates; $\mathrm{Au} @ \mathrm{Fe}_{3} \mathrm{O}_{4}$ and CS modified GCE; carbon-fiber electrode (CFE); Platinum nanoparticles (PNP) modified platinum disk electrode $(\mathrm{Pt})$.

\subsection{The Selectivity, Reproducibility, and Stability of the GH/GCE}

Amperometric measurements were performed to determine the selectivity of GH/GCE towards IAA/SA in the presence of interferents such as CA, ABA, GA3, AA, L-malic acid, L-Trp, L-Tyr, and L-Cys. Before measurements, the working potentials were first optimized in $0.1 \mathrm{M}$ phosphate buffer solution with a $\mathrm{pH}$ value of 2.5, and the results are displayed in Figure S3. As can be seen from the figure, the optimal working potential for amperometric measurements of IAA and SA were $0.8 \mathrm{~V}$ (Figure S2A, Supporting Information) and 1.0 V (Figure S3B, Supporting Information), respectively. The amperometric responses to IAA/SA and other substances are exhibited in Figure S3. The results (Figure S3, Supporting Information) show that the GH/GCE was very robust and its performance for IAA was unaffected by the presence of those interferents. However, the presence of $20.0 \mu \mathrm{M}$ IAA interfered with SA measurement when using amperometric measurement. This may be due to the amperometric response of IAA on GH/GCE at $1.0 \mathrm{~V}$ (Figure S3A, Supporting Information). Nonetheless, the above results indicate that the GH/GCE has good selectivity to IAA and SA. 
Three GH/GCEs were fabricated to evaluate the fabrication reproducibility of the sensor. These GH/GCEs were used to simultaneous detection of $80.0 \mu \mathrm{M}$ IAA and $60.0 \mu \mathrm{M}$ SA in $0.10 \mathrm{M} \mathrm{pH} 2.5$ phosphate buffer solution using LSV. The relative standard deviations (RSDs) of IAA and SA were $7.2 \%$ and $9.5 \%(n=3)$, respectively. The reproducibility of our sensor was assessed by detecting IAA $(80.0 \mu \mathrm{M})$ and SA $(60.0 \mu \mathrm{M})$ five times in succession with corresponding RSDs of $2.5 \%$ and $3.5 \%$. The storage (at $4{ }^{\circ} \mathrm{C}$ ) stability of GH/GCE was also investigated. The results show that the LSV response currents of IAA $(80.0 \mu \mathrm{M})$ and SA $(60.0 \mu \mathrm{M})$ decreased respectively by $2.1 \%$ and $4.0 \%$, after five days and by $4.3 \%$ and $9.1 \%$, after 10 days. These results indicate the acceptable reproducibility and good stability of our sensor.

\subsection{Detection of IAA and SA in Real Samples}

The proposed method was finally applied for the determination of IAA and SA in celery and tomato leaf samples, and the accuracy of the method was verified by recovery experiments. Using the calibration data (Figure 7B,C), the amount of IAA and SA present in celery and tomato leaf samples were determined as 5.02 and $4.00 \mu \mathrm{M}$, and 3.98 and $4.12 \mu \mathrm{M}$, respectively. Further to determine the recoveries, we spiked real samples with 4.0 and $40.0 \mu \mathrm{M}$ each of IAA and SA. The recovery results (spiked plus initial) were in the range from $94.9 \%$ to $105.2 \%$ (Table 2). These results indicate excellent sensor performance.

Table 2. Results of the recovery analysis of IAA and SA in vegetable samples $(n=3)$.

\begin{tabular}{ccccccc}
\hline Sample & $\begin{array}{c}\text { IAA Added } \\
(\boldsymbol{\mu})\end{array}$ & $\begin{array}{c}\text { SA Added } \\
(\boldsymbol{\mu} \mathbf{M})\end{array}$ & $\begin{array}{c}\text { IAA Detected } \\
(\boldsymbol{\mu M})\end{array}$ & $\begin{array}{c}\text { SA Detected } \\
(\boldsymbol{\mu M})\end{array}$ & $\begin{array}{c}\text { Recovery of IAA } \\
(\%)\end{array}$ & $\begin{array}{c}\text { Recovery of SA } \\
(\%)\end{array}$ \\
\hline Celery & - & - & 5.02 & 3.98 & & \\
\hline $\begin{array}{c}\text { Tomato } \\
\text { leaves }\end{array}$ & 40.00 & 40.00 & $45.30 \pm 0.07$ & $42.50 \pm 0.23$ & $100.6 \pm 0.16$ & $96.6 \pm 0.52$ \\
\hline
\end{tabular}

\section{Conclusions}

The electrochemical oxidation of IAA/SA were investigated, and a selective and sensitive electrochemical sensor based on GH modified GCE was developed for simultaneous determination of IAA and SA. The prepared GH exhibited a porous and 3D networked structure, good conductivity, and excellent electrocatalytic activity, which enabled the GH/GCE to realize sensitive determination of IAA and SA. As IAA and SA were electrochemically oxidized at different potentials on the GH/GCE, and the oxidation currents of IAA and SA were proportional to the concentration of the detecting substances, the proposed sensor shows its ability for selective and simultaneous determination of IAA and SA. The developed method was demonstrated to have excellent accuracy in detecting IAA and SA in real vegetable samples, which makes it a potential sensor for practical detection of IAA and SA in plants.

Supplementary Materials: The following are available online at http://www.mdpi.com/1424-8220/19/24/5483/s1, Figure S1. LSV recorded on GH-3.5 modified GCE at $100 \mathrm{mV} \mathrm{s}-1$ in the presence of $80 \mu \mathrm{M} \mathrm{IAA}$ and $60 \mu \mathrm{M}$ SA in PBS at different pHs. Figure S2. LSV of GH/GCE of $100 \mathrm{mV} \mathrm{s}-1$ in the presence of $80 \mu \mathrm{M}$ IAA and $60 \mu \mathrm{M}$ SA in $0.10 \mathrm{M}$ PBS at pH 2.5 using GCEs modified with different GHs. Figure S3. Working potential optimization for amperometric measurements of IAA $(10 \mu \mathrm{M})(\mathbf{A})$ and SA $(20 \mu \mathrm{M})(\mathbf{B})$. Figure S4. (A) Amperometric response of $\mathrm{GH} / \mathrm{GCE}$ in $0.10 \mathrm{M}$ PBS (pH 2.5) at $+0.80 \mathrm{~V}$ for the addition of $10 \mu \mathrm{M} \mathrm{IAA} ; 200 \mu \mathrm{M}$ CA, ABA, GA3, and L-Malic acid; $20 \mu \mathrm{M}$ L-Tyr, SA, AA L-Trp, and L-Cys. (B) Amperometric response of GH/GCE in 0.10 M PBS (pH 2.5) at $+1.00 \mathrm{~V}$ for the addition of $10 \mu \mathrm{M} \mathrm{SA} ; 200 \mu \mathrm{M} \mathrm{CA}, \mathrm{ABA}, \mathrm{GA3}$, and L-Malic acid; $20 \mu \mathrm{M} \mathrm{L-Tyr}$, AA, L-Trp, L-Cys, and IAA. Table S1. Fitting values of the equivalent circuit elements for different working electrodes (WE).

Author Contributions: Conceptualization, X.C. and Y.Y.; methodology, X.C. and X.Z.; validation, X.C., Y.Y. and X.X.; formal analysis, X.C.; investigation, X.C. and Y.Y.; resources, X.C. and Y.Y.; data curation, X.C. and X.Z.; writing-original draft preparation, X.C. and X.Z.; writing-review and editing, X.X., S.H. and Y.Y.; visualization, Y.Y.; supervision, X.C. and Y.Y.; project administration, Y.Y.; funding acquisition, X.C., X.X. and Y.Y. 
Funding: This research was supported by the National Natural Science Foundation of China $(31772099,31401573$ and 21505071), the China Postdoctoral Science Foundation (2017T100446, 2016M592050), the Natural Science Foundation of Anhui Province (1908085MC98), the Key Research and Development Program of Anhui Province (201904a06020030), and the Fundamental Research Funds for the Central Universities (JZ2018HGTB0245).

Conflicts of Interest: The authors declare no conflict of interest.

\section{References}

1. Su, C.; Liu, C.; Chen, J.; Chen, Z.; He, Z. Simultaneous determination of zeatin and systemin by coupling graphene oxide-protected aptamers with catalytic recycling of DNase i. Sens. Actuators B Chem. 2016, 230, 442-448. [CrossRef]

2. Zhang, X.; Niu, J.; Zhang, X.; Xiao, R.; Lu, M.; Cai, Z. Graphene oxide-SiO ${ }_{2}$ nanocomposite as the adsorbent for extraction and preconcentration of plant hormones for HPLC analysis. J. Chromatogr. B 2017, 1046, 58-64. [CrossRef] [PubMed]

3. Gupta, V.; Kumar, M.; Brahmbhatt, H.; Reddy, C.R.K.; Seth, A.; Jha, B. Simultaneous determination of different endogenetic plant growth regulators in common green seaweeds using dispersive liquid-liquid microextraction method. Plant Physiol. Biochem. 2011, 49, 1259-1263. [CrossRef] [PubMed]

4. Sun, L.J.; Xie, Y.; Yan, Y.F.; Yang, H.; Gu, H.Y.; Bao, N. Paper-based analytical devices for direct electrochemical detection of free IAA and SA in plant samples with the weight of several milligrams. Sens. Actuators B Chem. 2017, 247, 336-342. [CrossRef]

5. Seo, H.; Kriechbaumer, V.; Park, W.J. Modern quantitative analytical tools and biosensors for functional studies of auxin. J. Plant Biol. 2016, 59, 93-104. [CrossRef]

6. Yang, L.; Chen, Y.; Zhao, S.; Zhang, W.; Du, H.; Deng, Z.; Zhang, S. Simultaneous determination of indole-3-acetic acid and indole-3-butyric acid in plant by field-amplified sample stacking open-tubular capillary electrochromatography based on solid-phase extraction with calixarene sorbent. Chromatographia 2016, 79, 243-254. [CrossRef]

7. Muhammad, N.; Subhani, Q.; Wang, F.; Lou, C.; Liu, J.; Zhu, Y. Simultaneous determination of two plant growth regulators in ten food samples using ion chromatography combined with QuEChERS extraction method (IC-QuEChERS) and coupled with fluorescence detector. Food Chem. 2018, 241, 308-316. [CrossRef]

8. Wang, W.; He, M.; Chen, B.; Hu, B. Simultaneous determination of acidic phytohormones in cucumbers and green bean sprouts by ion-pair stir bar sorptive extraction-high performance liquid chromatography. Talanta 2017, 170, 128-136. [CrossRef]

9. Wu, Y.; Hu, B. Simultaneous determination of several phytohormones in natural coconut juice by hollow fiber-based liquid-liquid-liquid microextraction-high performance liquid chromatography. J. Chromatogr. A 2009, 1216, 7657-7663. [CrossRef]

10. Li, G.; Liu, S.; Sun, Z.; Xia, L.; Chen, G.; You, J. A simple and sensitive HPLC method based on pre-column fluorescence labelling for multiple classes of plant growth regulator determination in food samples. Food Chem. 2015, 170, 123-130. [CrossRef]

11. Perin, E.C.; Crizel, R.L.; Galli, V.; da Silva Messias, R.; Rombaldi, C.V.; Chaves, F.C. Extraction and quantification of abscisic acid and derivatives in strawberry by LC-MS. Food Anal. Methods 2018, 11, 2547-2552. [CrossRef]

12. Suárez-Pantaleón, C.; Esteve-Turrillas, F.A.; Mercader, J.V.; Agulló, C.; Abad-Somovilla, A.; Abad-Fuentes, A. Development and validation of a direct competitive monoclonal antibody-based immunoassay for the sensitive and selective analysis of the phytoregulator forchlorfenuron. Anal. Bioanal. Chem. 2012, 403, 2019-2026. [CrossRef] [PubMed]

13. Lu, S.; Wen, Y.; Bai, L.; Liu, G.; Chen, Y.; Du, H.; Wang, X. pH-controlled voltammetric behaviors and detection of phytohormone 6-benzylaminopurine using MWCNT/GCE. J. Electroanal. Chem. 2015, 750, 89-99. [CrossRef]

14. Zhou, Y.; Xu, Z.; Wang, M.; Meng, X.; Yin, H. Electrochemical immunoassay platform for high sensitivity detection of indole-3-Acetic acid. Electrochim. Acta 2013, 96, 66-73. [CrossRef]

15. Liu, F.; Tang, J.; Xu, J.; Shu, Y.; Xu, Q.; Wang, H.; Hu, X. Low potential detection of indole-3-acetic acid based on the peroxidase-like activity of hemin/reduced graphene oxide nanocomposite. Biosens. Bioelectron. 2016, 86, 871-878. [CrossRef] [PubMed] 
16. Tvorynska, S.; Josypčuk, B.; Barek, J.; Dubenska, L. Electrochemical behavior and sensitive methods of the voltammetric determination of food azo dyes amaranth and allura red AC on amalgam electrodes. Food Anal. Methods 2019, 12, 409-421. [CrossRef]

17. Gan, T.; Hu, C.; Chen, Z.; Hu, S. A disposable electrochemical sensor for the determination of indole-3-acetic acid based on poly(safranine T)-reduced graphene oxide nanocomposite. Talanta 2011, 85, 310-316. [CrossRef]

18. Chandler, J.W. Auxin as compère in plant hormone crosstalk. Planta 2009, 231, 1-12. [CrossRef]

19. Rivas-San Vicente, M.; Plasencia, J. Salicylic acid beyond defence: Its role in plant growth and development. J. Exp. Bot. 2011, 62, 3321-3338. [CrossRef]

20. Shakirova, F.M.; Sakhabutdinova, A.R.; Bezrukova, M.V.; Fatkhutdinova, R.A.; Fatkhutdinova, D.R. Changes in the hormonal status of wheat seedlings induced by salicylic acid and salinity. Plant Sci. 2003, 164, 317-322. [CrossRef]

21. Park, J.E.; Park, J.Y.; Kim, Y.S.; Staswick, P.E.; Jeon, J.; Yun, J.; Kim, S.Y.; Kim, J.; Lee, Y.H.; Park, C.M. GH3-mediated auxin homeostasis links growth regulation with stress adaptation response in Arabidopsis. J. Biol. Chem. 2007, 282, 10036-10046. [CrossRef] [PubMed]

22. Sun, L.; Liu, X.; Gao, L.; Lu, Y.; Li, Y.; Pan, Z.; Bao, N.; Gu, H. Simultaneous electrochemical determination of indole-3-acetic acid and salicylic acid in pea roots using a multiwalled carbon nanotube modified electrode. Anal. Lett. 2015, 48, 1578-1592. [CrossRef]

23. Lu, S.; Bai, L.; Wen, Y.; Li, M.; Yan, D.; Zhang, R.; Chen, K. Water-dispersed carboxymethyl cellulose-montmorillonite-single walled carbon nanotube composite with enhanced sensing performance for simultaneous voltammetric determination of two trace phytohormones. J. Solid State Electrochem. 2015, 19, 2023-2037. [CrossRef]

24. Xu, Y.; Sheng, K.; Li, C.; Shi, G. Self-assembled graphene hydrogel. ACS Nano 2010, 4, 4324-4330. [CrossRef] [PubMed]

25. Song, Z.; Li, W.; Bao, Y.; Sun, Z.; Gao, L.; Nawaz, M.H.; Han, D.; Niu, L. Enhanced pseudocapacitance and electrolyte-wettability of graphene hydrogels to tailor high mass loading all-solid-state supercapacitor with ultra-high volumetric energy density. Carbon 2018, 136, 46-53. [CrossRef]

26. Song, H.; Zhang, X.; Liu, Y.; Su, Z. Developing graphene-based nanohybrids for electrochemical sensing. Chem. Rec. 2019, 19, 534-549. [CrossRef]

27. Zhang, J.; Li, R.; Li, Z.; Liu, J.; Gu, Z.; Wang, G. Synthesis of nitrogen-doped activated graphene aerogel/gold nanoparticles and its application for electrochemical detection of hydroquinone and o-dihydroxybenzene. Nanoscale 2014, 6, 5458-5466.

28. Kokulnathan, T.; Ramaraj, S.; Chen, S.-M.; Yang, H.-Y. Eco-friendly synthesis of biocompatible pectin stabilized graphene nanosheets hydrogel and their application for the simultaneous electrochemical determination of dopamine and paracetamol in real samples. J. Electrochem. Soc. 2018, 165, B240-B249. [CrossRef]

29. Rahmani, T.; Bagheri, H.; Behbahani, M.; Hajian, A.; Afkhami, A. Modified 3D graphene-Au as a novel sensing layer for direct and sensitive electrochemical determination of carbaryl pesticide in fruit, vegetable, and water samples. Food Anal. Methods 2018, 11, 3005-3014. [CrossRef]

30. Zhang, W.; Chen, Z.; Guo, X.; Jin, K.; Wang, Y.X.; Li, L.; Zhang, Y.; Wang, Z.; Sun, L.; Zhang, T. N/S co-doped three-dimensional graphene hydrogel for high performance supercapacitor. Electrochim. Acta 2018, 278, 51-60. [CrossRef]

31. Zhu, Q.; Bao, J.; Huo, D.; Yang, M.; Hou, C.; Guo, J.; Chen, M.; Fa, H.; Luo, X.; Ma, Y. 3D Graphene hydrogel-Gold nanoparticles nanocomposite modified glassy carbon electrode for the simultaneous determination of ascorbic acid, dopamine and uric acid. Sens. Actuators B Chem. 2016, 238, 1316-1323. [CrossRef]

32. Zhu, Q.; Bao, J.; Huo, D.; Yang, M.; Wu, H.; Hou, C.; Zhao, Y.; Luo, X.; Fa, H. 3DGH-Fc based electrochemical sensor for the simultaneous determination of ascorbic acid, dopamine and uric acid. J. Electroanal. Chem. 2017, 799, 459-467. [CrossRef]

33. Xie, Y.; Sheng, X.; Xie, D.; Liu, Z.; Zhang, X.; Zhong, L. Fabricating graphene hydrogels with controllable pore structure via one-step chemical reduction process. Carbon 2016, 109, 637-680. [CrossRef]

34. Meng, X.; Lu, L.; Sun, C. Green synthesis of three-dimensional $\mathrm{MnO}_{2} /$ graphene hydrogel composites as a high-performance electrode material for supercapacitors. ACS Appl. Mater. Interfaces 2018, 10, 16474-16481. [CrossRef] 
35. Wu, Q.; Sun, Y.; Bai, H.; Shi, G. High-performance supercapacitor electrodes based on graphene hydrogels modified with 2-aminoanthraquinone moieties. Phys. Chem. Chem. Phys. 2011, 13, 11193-11198. [CrossRef]

36. Cao, X.; Zhu, X.; He, S.; Xu, X.; Ye, Y.; Gunasekaran, S. Gold nanoparticle-doped three-dimensional reduced graphene hydrogel modified electrodes for amperometric determination of indole-3-acetic acid and salicylic acid. Nanoscale 2019, 11, 10247-10256. [CrossRef]

37. Hao, N.; Hua, R.; Chen, S.; Zhang, Y.; Zhou, Z.; Qian, J.; Liu, Q.; Wang, K. Multiple signal-amplification via $\mathrm{Ag}$ and $\mathrm{TiO}_{2}$ decorated $3 \mathrm{D}$ nitrogen doped graphene hydrogel for fabricating sensitive label-free photoelectrochemical thrombin aptasensor. Biosens. Bioelectron. 2018, 101, 14-20. [CrossRef]

38. Hao, N.; Zhang, X.; Zhou, Z.; Hua, R.; Zhang, Y.; Liu, Q.; Qian, J.; Li, H.; Wang, K. AgBr nanoparticles/3D nitrogen-doped graphene hydrogel for fabricating all-solid-state luminol-electrochemiluminescence Escherichia coli aptasensors. Biosens. Bioelectron. 2017, 97, 377-383. [CrossRef]

39. Li, J.; Xie, J.; Gao, L.; Li, C.M. Au nanoparticles-3D graphene hydrogel nanocomposite to boost synergistically in situ detection sensitivity toward cell-released nitric oxide. ACS Appl. Mater. Interfaces 2015, 7, 2726-2734. [CrossRef]

40. Cao, X.; Xu, H.; Ding, S.; Ye, Y.; Ge, X.; Yu, L. Electrochemical determination of sulfide in fruits using alizarin-reduced graphene oxide nanosheets modified electrode. Food Chem. 2016, 194, 1224-1229. [CrossRef]

41. Ye, Y.; Ding, S.; Ye, Y.; Xu, H.; Cao, X.; Liu, S.; Sun, H. Enzyme-based sensing of glucose using a glassy carbon electrode modified with a one-pot synthesized nanocomposite consisting of chitosan, reduced graphene oxide and gold nanoparticles. Microchim. Acta 2015, 182, 1783-1789. [CrossRef]

42. Cançado, L.G.; Jorio, A.; Ferreira, E.H.M.; Stavale, F.; Achete, C.A.; Capaz, R.B.; Moutinho, M.V.O.; Lombardo, A.; Kulmala, T.S.; Ferrari, A.C. Quantifying defects in graphene via Raman spectroscopy at different excitation energies. Nano Lett. 2011, 11, 3190-3196. [CrossRef] [PubMed]

43. Bhaskaram, D.S.; Govindaraj, G. Carrier transport in reduced graphene oxide probed using Raman spectroscopy. J. Phys. Chem. C 2018, 122, 10303-10308. [CrossRef]

44. Li, X.; Wang, Q.; Zhao, Y.; Wu, W.; Chen, J.; Meng, H. Green synthesis and photo-catalytic performances for ZnO-reduced graphene oxide nanocomposites. J. Colloid Interface Sci. 2013, 411, 69-75. [CrossRef] [PubMed]

45. Kwon, S.; Yoon, Y.; Ahn, J.; Lim, H.; Kim, G.; Kim, J.H.; Choi, K.B.; Lee, J.J. Facile laser fabrication of high quality graphene-based microsupercapacitors with large capacitance. Carbon 2018, 137, 136-145. [CrossRef]

46. Laviron, E. General expression of the linear potential sweep voltammogram in the case of diffusionless electrochemical systems. J. Electroanal. Chem. Interfacial Electrochem. 1979, 101, 19-28. [CrossRef]

47. Yardim, Y.; Erez, M.E. Electrochemical behavior and electroanalytical determination of indole-3-acetic acid phytohormone on a boron-doped diamond electrode. Electroanalysis 2011, 23, 667-673. [CrossRef]

48. Rawlinson, S.; McLister, A.; Kanyong, P.; Davis, J. Rapid determination of salicylic acid at screen printed electrodes. Microchem. J. 2018, 137, 71-77. [CrossRef]

49. de Ribeiro, C.L.; Santos, J.G.M.; de Souza, J.R.; Pereira-da-Silva, M.A.; Paterno, L.G. Electrochemical oxidation of salicylic acid at ITO substrates modified with layer-by-layer films of carbon nanotubes and iron oxide nanoparticles. J. Electroanal. Chem. 2017, 805, 53-59. [CrossRef]

50. Sun, L.J.; Pan, Z.Q.; Xie, J.; Liu, X.J.; Sun, F.T.; Song, F.M.; Bao, N.; Gu, H.Y. Electrocatalytic activity of salicylic acid on $\mathrm{Au} @ \mathrm{Fe}_{3} \mathrm{O}_{4}$ nanocomposites modified electrode and its detection in tomato leaves infected with Botrytis cinerea. J. Electroanal. Chem. 2013, 706, 127-132. [CrossRef]

51. Park, J.; Eun, C. Electrochemical behavior and determination of salicylic acid at carbon-fiber electrodes. Electrochim. Acta 2016, 194, 346-356. [CrossRef]

52. Wang, Z.; Ai, F.; Xu, Q.; Yang, Q.; Yu, J.H.; Huang, W.H.; Zhao, Y.D. Electrocatalytic activity of salicylic acid on the platinum nanoparticles modified electrode by electrochemical deposition. Colloids Surf. B Biointerfaces 2010, 76, 370-374. [CrossRef] [PubMed]

(C) 2019 by the authors. Licensee MDPI, Basel, Switzerland. This article is an open access article distributed under the terms and conditions of the Creative Commons Attribution (CC BY) license (http://creativecommons.org/licenses/by/4.0/). 